\title{
Purposes in law and in life: An experimental investigation of purpose
}

\section{attribution*}

\author{
Guilherme da Franca Couto Fernandes de Almeida \\ guilherme.almeida@yale.edu \\ Joshua Knobe \\ joshua.knobe@yale.edu \\ Noel Struchiner \\ noel@puc-rio.br \\ Ivar Rodriguez Hannikainen \\ ivar@ugr.es
}

\begin{abstract}
There has been considerable debate in legal philosophy about how to attribute purposes to rules. Separately, within cognitive science, there has been a growing body of research concerned with questions about how people ordinarily attribute purposes. Here, we argue that these two separate fields might be connected by experimental jurisprudence. Across four studies, we find evidence for the claim that people use the same criteria to attribute purposes to physical objects and to rules. In both cases, purpose attributions appear to be governed not so much by original intention or by moral value as by current practice. We argue that these findings in the cognitive science of purpose attribution have implications for jurisprudential questions involving purposivist legal interpretation.
\end{abstract}

\section{Introduction}

\footnotetext{
*We would like to thank Brian Flanagan, Danilo dos Santos Almeida, Fábio Shecaira, Ivar Hartmann, James Macleod, Lawrence Solum, Leandro Molhano Ribeiro, Lucas Miotto, Kevin Tobia, and Thomaz Pereira for their valuable feedback. This research was made possible through support from the National Council of Scientific and Technological Development (CNPq; grant number: 309735/2019-0), the Carlos Chagas Filho Research Support Foundation (FAPERJ; grant number: E-26/201.071/2021), the Coordenação de Aperfeiçoamento de Pessoal de Nível Superior (CAPES; grant number: 001), and the Spanish Ministry of Science, Innovation and Universities (MICINN; grant number: IJC2018-037682-I).
} 
When people are trying to make sense of ordinary objects, they often attribute purposes to those objects. Thus, a person might say "This knife is for cutting bread" or "That peg is for hanging coats." Research in cognitive science has investigated the ways in which people make these attributions, and we now know quite a bit about the criteria people use to determine whether a given object has a given purpose. ${ }^{1}$

Purposes are also extremely important in law. Scholars such as Lon Fuller, ${ }^{2}$ Henry Hart and Albert Sacks, ${ }^{3}$ and Aharon Barak ${ }^{4}$ have long championed the role of purpose in legal interpretation. They argue that legal rules should be read through purposive lenses. However, there is disagreement about the specifics. As we will see, some argue that purposes ought to be identified with the original intentions of the lawmakers, others think that they should be defined by the moral principles that best justify the interpreted rule, while others still argue that purposes should reflect current practices surrounding rules. Importantly, how ordinary people attribute purposes might be relevant to the normative debate. After all, publicity is an important concern in legal interpretation: judges should interpret rules in ways that resemble ordinary people's interpretation.

So far, the literatures investigating purposes in law and in life have developed completely in parallel, with few connections explicitly drawn between the two fields. In this paper, we aim to bridge this gap. Specifically, we will use the methods and prior knowledge of the cognitive sciences to tackle the empirical question about how people attribute purposes to legal rules, and in which ways this kind of purpose attribution is similar or dissimilar to the more well-studied area of the attribution of purposes to physical objects.

First, we present an overview of existing legal scholarship on purposivism. We distinguish between three possible views: one that emphasizes the original intentions of the legislature ("intentionalism"), one that emphasizes the normative goal that presents the rule under its best possible light (“objective purposivism”), and, finally, a view that hasn't received nearly as much

\footnotetext{
${ }^{1}$ Adee Matan and Susan Carey, 'Developmental Changes Within the Core of Artifact Concepts' (2001) 78 Cognition 1; Tim P German and Susan C Johnson, 'Function and the Origins of the Design Stance' (2002) 3 Journal of Cognition and Development 279; Deborah R Siegel and Maureen A Callanan, 'Artifacts as Conventional Objects' (2007) 8 Journal of Cognition and Development 183; Sehrang Joo, Sami R Yousif and Joshua Knobe, 'Teleology Beyond Explanation' (forthcoming) Mind \& Language.

2 Lon Fuller, 'Positivism and Fidelity to Law' (1958) 71 Harvard Law Review 630.

${ }^{3}$ Henry M Hart and Albert M Sacks, The Legal Process: Basic Problems in the Making and Application of Law (Foundation Press 1994).

${ }^{4}$ Aharon Barak, Purposive Interpretation in Law (Princeton University Press 2005).
} 
discussion within the existing literature and that we will call "current practice purposivism." Second, we briefly review existing cognitive science research about purposes. This research provides insights into people's way of attributing purposes, but it leaves unanswered some of the most pressing questions we face when looking at purpose attribution in the law. In short, examining the evidence from existing cognitive science research is not enough to settle the question as to which form of legal purposivism best accords with people's ordinary understanding. Doing so necessitates direct experimental evaluation.

We therefore report the results of four experiments involving both lay people and lawyers. The results show that people's ordinary way of attributing purposes to laws does not prioritize either original intentions or morality. Rather, people prioritize current practice. Thus, to the extent that the courts attribute purposes using either original intentions or morality, this approach should not be conceptualized as a straightforward application of people's ordinary understanding of the purposes of laws. It should be conceptualized instead as a departure from people's ordinary understanding that would require some independent justification.

\section{A. Legal Purposes and the Cognitive Science of Purpose Attribution}

Within the existing literature, there has been a complex debate regarding the attribution of purposes to rules, and legal scholars have developed numerous different arguments that appear to favor one alternative or another. ${ }^{5}$ Our aim here is to add one more consideration to the mix. In addition to everything that has already been discussed within existing work, one relevant consideration in deciding between these different accounts is the cognitive science of people's ordinary purpose attributions.

To establish that this consideration is relevant, we will need to argue for two claims - an empirical claim and a normative claim. The empirical claim is that the criteria people ordinarily use to attribute purposes to laws are the very same criteria that they use to attribute purposes to objects more generally. The normative claim is that facts about the criteria people ordinarily use to attribute purposes to laws can give us at least some reason to prefer certain criteria over others in making

\footnotetext{
${ }^{5}$ For an overview of the existing kinds of legal purposivism, see Barak (n 4). Our own summary is given in Section 2.
} 
legal judgments. Taken together, these two claims allow us to see why evidence about how people attribute purposes to objects more generally is relevant to those interested in legal interpretation.

Let's begin with the empirical claim. One possibility would be that people attribute purposes to laws using domain-specific criteria. That is, it might be that the criteria people use in attributing purposes to laws are quite different from the criteria they use in attributing purposes to other sorts of objects. If this does turn out to be the case, then findings about how people attribute purposes to objects more generally will not be relevant to legal interpretation. Alternatively, it might turn out that people attribute purposes to laws using domain-general criteria. That is, people may attribute purposes to laws using the same basic criteria that they employ when attributing purposes to physical objects like knives or hammers. To the extent that we find evidence for this sort of domaingenerality, we can begin leveraging the enormous existing literature on how people attribute purposes to physical objects to make progress on questions about how people attribute purposes to laws.

This empirical question is part of a much larger inquiry about the degree to which people's judgments within the legal domain rely on domain-specific vs. domain-general criteria. Over the past few years, there have been a number of attempts to explore these sorts of questions through systematic empirical studies, and the results seem to indicate that some judgments are made using domain specific criteria while others are made using domain-general criteria. For instance, research on statutory interpretation shows that people interpret certain words (e.g., "vehicle") differently when reading it in the context of a statute (e.g., "no vehicles in the park") compared to when simply judging whether or not certain objects are vehicles, which suggests that parts of legal interpretation are domain-specific. ${ }^{6}$ In contrast, recent empirical work on the "reasonable person" standard suggests that people apply it by employing more general criteria about what it means for something to count as "reasonable" (e.g., to say whether a certain amount of time counts as "a reasonable amount of TV to watch in a day"). ${ }^{7}$ In light of these findings, we did not start out this project with a definite hypothesis as to whether people's criteria for the attribution of purposes to laws would be domain-specific or domain-general. Instead, the studies reported here were designed in part to

\footnotetext{
${ }^{6}$ Kevin P Tobia, 'Testing Ordinary Meaning’ (2020) 133 Harvard Law Review 726.

7 Kevin P Tobia, 'How People Judge What Is Reasonable' (2018) 70 Alabama Law Review 293.
} 
provide evidence about that very issue. As we will see, our results seem to suggest that people attribute purposes to laws using domain-general criteria.

Let's turn now to the normative claim. There is widespread agreement among legal scholars about the normative importance of publicity. Legal rules address all kinds of people, purporting to influence their behavior in meaningful ways. ${ }^{8}$ In order to do that fairly, rules must be appropriately understood by their subjects. ${ }^{9}$ Even Hart and Fuller, who find themselves at opposite sides on many jurisprudential issues, agree that publicity is crucial for law. Hart famously remarked: "If it were not possible to communicate general standards of conduct, which multitudes of individuals could understand, without further direction (...), nothing that we now recognize as law could exist."10 Fuller, in no unclear terms sustained that "a failure to publicize or at least to make available to the affected party, the rules he is expected to observe" and "a failure to make rules understandable" would be routes for disaster in an attempt to maintain a system of legal rules. ${ }^{11}$ This entails not only an obligation on the part of lawmakers, who should write clear rules, but also on judges, who should interpret the statutes in a way that is consistent with ordinary meaning.

Publicity so understood is also important in the interpretation of purposes. ${ }^{12}$ First, purposivist interpretation is often defended precisely because it helps bring legal decisions in line with ordinary intuitions - which is especially true when, as is often objected against publicity, subjects don't know the exact text of legal rules. ${ }^{13}$ Second, if there are several candidates that may play the role of purpose in legal interpretation, we should prefer the one that's most likely to guide ordinary readings of the rule for the precise reasons articulated by Hart and Fuller in the previous paragraph (i.e., rules must be understood by its addressees in order to guide conduct). Thus, those

\footnotetext{
${ }^{8}$ Publicity is always relative to a rule's addressees. Making a rule accessible to the general public requires something different than making it accessible to highly specialized audiences (e.g., the financial sector).

${ }^{9}$ For an extended argument about the importance of publicity in law, see Joseph Raz, The Authority of Law: Essays on Law and Morality (Clarendon Press, 1979) chp. 11. Legal philosophers often break down what we are calling publicity into two distinct requirements: publicity proper (the idea that laws should be made public) and intelligibility (the idea that subjects should be able to understand rules). We do not mean to downplay the importance of the distinction, but nothing in our reasoning turns on it.

${ }^{10}$ HLA Hart, The Concept of Law (2nd edn, Clarendon Press 1994) 124.

${ }^{11}$ Lon Fuller, The Morality of Law (Yale University Press, 1969) 39.

${ }^{12}$ Neither Hart, Fuller, or Raz explicitly apply the publicity-based reasoning to the debate about purpose attribution, but this seems to be a very natural and uncontroversial extension of their ideas.

${ }^{13}$ For a response to this objection, see Fuller (n 11) 50-51.
} 
committed to the argument from publicity have a pro tanto reason to follow the majority in selecting which kind of purpose should inform their rule violation judgments.

In saying all of this, we certainly don't mean to suggest that publicity is the only relevant consideration in choosing between different accounts of legal purpose. On the contrary, this is a complex issue, and legal scholars have identified numerous different considerations that bear on it. Our point is simply that publicity is one of the relevant considerations. Ultimately, after we consider all relevant reasons, we might well conclude we should adopt an approach to legal interpretation in which we attribute purposes to law using criteria that differ from people's ordinary criteria. Yet, even then, we would not be concluding that facts about people's ordinary criteria are irrelevant. Rather, facts about people's ordinary criteria do give us some reason to prefer certain criteria over others; it's just that this reason can potentially be outweighed by other reasons.

Put together, these two claims (about the domain-generality of purpose attribution and about publicity) would suggest that facts about how ordinary people attribute purposes to non-legal objects can give us valuable evidence about how the courts should attribute purposes to laws. Many legal philosophers already seem to accept them, not only valuing publicity, but also drawing examples from non-legal domains. Fuller, for instance, employs an analogy involving a physical object, ${ }^{14}$ while Alexander and Sherwin discuss how one would interpret a note from one's mother. ${ }^{15}$ This is the approach we will be adopting and extending here, by considering and producing relevant empirical evidence.

\section{Purposes in Legal Interpretation}

The preceding section helps us see what it takes to connect legal purposivism to the broader empirical project of understanding ordinary purpose attribution, but it contains very little about what we mean by legal purposivism and why we should care about it. To see the relevance of purposes for legal interpretation, it pays to consider an example where text and purpose collide.

Consider the case of John Yates, a fisherman who was caught with illegally undersized fish in his boat. 'To prevent federal authorities from confirming that he had harvested undersized fish,

\footnotetext{
14 Lon Fuller (n 11) 84-7.

15 Larry Alexander and Emily Sherwin, Demystifying Legal Reasoning (Cambridge University Press, 2008$) 133$.
} 
Yates ordered a crew member to toss the suspect catch into the sea. For this offense, he was charged with, and convicted of, violating $[\ldots]^{16}$ a rule against destroying a 'tangible object." ${ }^{, 17}$ A court of appeals heard the case and decided that the fisherman was in violation of the rule because he destroyed fish, and fish are, after all, tangible objects. Eventually, the case reached the U.S. Supreme Court. Critics of the court of appeals' decision noted that it 'never asked if treating a fish as a "tangible object" for purposes of [the rule] makes sense. (...) In keeping with the obvious legislative purpose of cracking down on accounting firms and other (...) professionals who aid and abet fraudulent financial reporting by corporations, the law applies to "record[s], document[s], or tangible object[s]" in which it is possible to 'make [ a false entry'. ${ }^{18}$ In other words, even though the rule's text recommended the result achieved by the court, it should have interpreted the statute according to its purpose. The main argument in the plurality opinion agreed. ${ }^{19}$

Even though the U.S. judiciary has been shifting towards textualism, ${ }^{20}$ the influence of purpose in Yates is not a one-off event, especially when one takes a more international approach. Commenting on current statutory interpretation, Burrows collates a series of judicial statements to show the importance of a purposivist outlook. For instance: "During the last 30 years, there has been a shift away from the literalist approach to purposive methods of construction" (Lord Steyn), “The court's task, within the permissible bounds of interpretation, is to give effect to Parliament's purpose" (Lord Bingham), and "The pendulum has swung towards purposive methods of construction.[...] [N] owadays the shift towards purposive interpretation is not in doubt" (Lord Steyin, once more). ${ }^{21}$ Philosophers such as Lon Fuller have long argued for the centrality of purpose in legal reasoning. ${ }^{22}$ But even Fuller's most famous opponent, Herbert Hart, agreed that purpose had an important role to play in legal interpretation: according to him, where the text isn't clear "we must decide the [unclear] cases rationally by reference to social aims." ${ }^{23}$ Recent work goes beyond

\footnotetext{
${ }^{16}$ Yates v. United States, 135 S. Ct. 1074.

1718 U. S. C. \$1519.

${ }^{18}$ Stephen F Smith, 'Yates v. United States: A Case Study in Overcriminalization' (2014) 163 University of Pennsylvania Law Review Online 147, 149. The emphasis comes from the original.

${ }^{19}$ Yates $v$. United States (n 16).

${ }^{20}$ As evidenced by Justice Elena Kagan's famous "we're all textualists now" remark. See Elena Kagan, The Scalia Lecture: A Dialogue with Justice Kagan on the Reading of Statutes, Harvard Law Today (Nov. 17, 2015), http://today.law.harvard.edu/in-scalia-lecture-kagan-discusses-statutory-interpretation.

${ }^{21}$ Andrew Burrows, Tbinking About Statutes: Interpretation, Interaction, Improvement (Cambridge University Press, 2018) 5-6.

22 (n 11).

${ }^{23}$ HLA Hart, 'Positivism and the Separation of Law and Morals' (1958) 71 Harvard Law Review 593, 614.
} 
that, showing that assessments of purpose violation influence rule violation judgments even where the text is clear. ${ }^{24}$ Thus, although there might be disagreement as to the extent of the importance of purposes to legal decision-making, it is hard to deny that they matter at least in some cases. Insofar as these cases are interesting, legal scholars should, and indeed have, studied purposes.

But what exactly is the purpose of a legal rule? Scholars have argued for at least three different answers: purpose might be identified as (a) the goal originally intended by the creator of a rule, (b) the normative goal that presents the rule under its best possible light, or (c) the goal that the rule advances under current practice.

\section{A. Intentionalism}

Intentionalism states that a rule's purpose is the goal that the rule creator (or the majority of the rule's creators, in the typical legislative case) originally intended it to fulfill. ${ }^{25}$ According to this view, to figure out what purpose recommended in Yates it would be necessary to establish what the legislature intended to accomplish with the rule (by, for instance, consulting legislative history). ${ }^{26}$ This strategy is sometimes referred to as uncovering the "subjective purpose" of the rule. ${ }^{27}$

Why should we defer to the intentions of the majority of lawmakers in legal interpretation? Intentionalists such as Alexander and Prakash, ${ }^{28}$ Alexander and Sherwin, ${ }^{29}$ Knapp and Michaels, ${ }^{30}$ and Fish ${ }^{31}$ offer at least two answers to this question. ${ }^{32}$ First, they argue that the interpreters of a text

\footnotetext{
24 Stephen M Garcia, Patricia Chen, and Matthew T Gordon, 'The Letter Versus the Spirit of the Law: A Lay Perspective on Culpability' (2014) 9 Judgment and Decision Making 479; Jessica Bregant, Isabel Wellbery, and Alex Shaw, 'Crime but not Punishment? Children are More Lenient Toward Rule-breaking when the "Spirit of the Law” is Unbroken' (2019) 178 Journal of Experimental Child Psychology 266; Noel Struchiner, Ivar Hannikainen, and Guilherme FCF Almeida, 'An Experimental Guide to Vehicles in the Park' (2020) 15 Judgment and Decision Making 312.

25 Our use of the term is partly stipulative. Intentionalism is also used with other senses, e.g., to label positions that affirm the importance of original intentions to meaning, instead of purposes (see $n$ 32).

26 That seems to be Smith's (n 18) suggestion and Ginsburg's opinion in Yates.

27 See Barak (n 4) 120.

${ }^{28}$ Larry Alexander and Saikrishna Prakash, "Is that English You're Speaking?” Why Intention Free Interpretation is an Impossibility' (2004) 41 San Diego Law Review 967.

29 Larry Alexander and Emily Sherwin (n 15).

30 Steven Knapp and Walter B Michaels, 'A Reply to Our Critics' in WJT Mitchell (ed), Against Theory: Literary Studies and the New Pragmatism (The University of Chicago Press, 1985); Steven Knapp and Walter B Michaels, Not a Matter of Interpretation' (2005) 42 San Diego Law Review 651.

31 Stanley Fish, 'There Is No Textualist Position' (2005) 42 San Diego Law Review 629; Stanley Fish, 'Intention Is All There Is: A Critical Analysis of Aharon Barak's Purposive Interpretation in Law' (2008) 29 Cardozo Law Review 1109.

32 These authors focus on a debate that is slightly different from the one about legal purposes. They are preoccupied with specific legal results - whether individual outcomes clash with the intentions of lawmakers - and often explicitly refuse to
} 
are always searching for the meaning intended by the author. They believe that this is true as a conceptual matter, and appeal to our intuitions by means of examples such as the following:

[...S] uppose [your] Mom has never mastered the distinction between autobahn and ottoman, and she leaves you a note requesting that you pull up the "autobahn" next to the sofa when she comes to visit. You surely know what to do, and it isn't to run a German highway through your den. ${ }^{33}$

This appeal might play a role in an argument from publicity: people ordinarily interpret (nonlegal) texts by relying on intentions. Furthermore, to make the example relevant, we must assume that there are important similarities between non-legal and legal interpretation. Those facts, plus the legal requirements of publicity, are enough to get us to the conclusion that judges ought to apply legal rules in an intentionalist fashion.

A second argument for intentionalism refers to legislative supremacy. ${ }^{34}$ If the separation of the roles of judge and lawmaker is supposed to ensure that the former carry out rules set by the latter, it is reasonable to assume that the meaning of a legal rule should be ascertained with reference to the original intentions of lawmakers.

Unlike the argument from publicity, this argument clearly does not apply to purpose attribution in other domains, such as the attribution of purposes to physical objects. It is a feature of legal reasoning that makes it so that we should privilege the intentions of one group of people (legislators) over our own. The argument is also independent from facts about ordinary intuitions. Even if no one actually refers to original intentions in ascertaining purpose, they still should do so if they wish to abide by the legislative supremacy doctrine.

It is important to note that these two arguments might pull in two opposite directions. For instance, it may be the case that people actually interpret purposes some other way, e.g., by attributing the purpose that casts the rule under its best possible light. On that account, publicity would recommend a different approach that competes with intentionalism. But the argument from

take their arguments to the higher levels of abstraction in which most (but perhaps not all) debates about purposes occur (Larry Alexander and Saikrishna Prakash (n 28) Appendix II; see also Jeffrey Goldsworthy, 'Legislative Intentions, Legislative Supremacy, and Legal Positivism' (2005) 42 San Diego Law Review 493; Larry Alexander and Emily Sherwin, n 13). Granted that they themselves might resist the label of intentionalists with regards to purposes, their arguments for this narrower form of intentionalism can also be mobilized (with no change other than the target) in favor of an intentionalist perspective on purposive interpretation (see Aharon Barak, $n$ 4).

33 Larry Alexander and Emily Sherwin, n. 15, 133.

34 See Jeffrey Goldsworthy (n 32); Aharon Barak (n 4) 128-9. 
legislative supremacy would still recommend intentionalism over the morally laden alternative. In that case, which argument should prevail? This is an important question that hasn't been tackled by intentionalists.

One last clarification is in order: the version of intentionalism considered here specifies that meaning derives from the intentions held by the rule-maker at the time of enactment. ${ }^{35}$ For this version, the original intentions behind a rule should inform purpose attribution, even if the original rulemakers themselves later change their minds. This is an important clarification because the legal debate about purposes generally contrasts goals that were pursued by one set of people in the past (the original intentions) with goals that are pursued in the present by a different group (the current practice). This ordinary situation confounds changes in who is invested with authority with changes in the goals that are pursued. Hence, proponents of intentionalism rarely consider the issue of intrapersonal changes in the intentions of rule-makers. In contrast, those are the cases featured in our experiments. Thus, some people who might otherwise be called intentionalists might wish to clarify their own positions away from the thesis we will test here. ${ }^{36}$

\section{B. Objective Purposivism}

The version of objective purposivism ${ }^{37}$ we consider in this paper (others are possible) says that we ought to attribute to a rule the purpose that best justifies it from the moral standpoint. Fuller, perhaps the philosopher most readily associated with purposivism, painted this idea in explicit contrast with intentionalism. For him, if law were like a collection of military orders, then "the task of the interpreter [would] be to discern as best he can the desires of the high command", 38

\footnotetext{
But deciding what the legislature would have said if it had been able to express its intention more precisely, or if it had not overlooked the interaction of its statute with other laws already on the books, or if it had realized that the supreme court was about to reverse a relevant precedent -
}

\footnotetext{
35 See Larry Alexander and Emily Sherwin (n 15) 141: 'What thing in the world makes it true that such-and-such was soand-so's intended meaning? [...] We assume that the interpreter is in search of the interpreter's mental state at the time of enactment [...]'.

${ }^{36}$ For experiments in the realm of physical objects that are relevant for these different forms of intentionalism, see Sehrang Joo, Sami Yousif, and Joshua Knobe (n 1). See also Deborah R Siegel and Maureen A Callanan (n 1).

37 The label follows Aharon Barak (n 4).

${ }^{38}$ Lon Fuller (n 11) 229.
} 
these and other like questions can remind us that there is something more to the task of interpreting statutes than simply "carrying out the intention of the legislature". ${ }^{39}$

Instead, to properly interpret legal rules, people must "put themselves in the position in which the accused found himself and ask what can reasonably be expected of a human being so placed" (emphasis added). Likewise, Hart and Sacks argued that legal interpretation should assume "that the legislature was made up of reasonable persons pursuing reasonable purposes reasonably". ${ }^{40}$ This stance has many other followers. For instance, some self proclaimed Dworkinians are objective purposivists: "[...] what guides the interpretative attitude of a Dworkinian interpreter is a moral purpose, a value that is capable of providing a justification of the practice being interpreted". ${ }^{41}$

Why should judges be objective purposivists? One way to defend that claim involves the requirement of publicity: if we accept that people mostly use morality to ascribe purpose outside the legal domain, then we should also use these same criteria when ascribing purposes to rules (assuming that the two domains are relevantly similar).

There are also other ways to defend the same conclusion. For instance, one can simply point towards the morally desirable quality of the results engendered by such an interpretive stance as reason to prefer it. This second argument claims that interpretation according to the best possible moral purpose is justified because it ensures better results than the alternatives. As with the argument from legislative supremacy, advanced in favor of intentionalism, this argument is insensitive to people's intuitions regarding purpose attribution: even if no one does actually follow this interpretative strategy, people should do so provided that they care about morally good results. Moreover, achieving morally good results seems to be one of the goals prototypically pursued by legal systems. This means that the argument from good results might be more salient in law than in other domains. Just as with intentionalism, it is also the case that the two arguments for objective purposivism we reviewed might point towards different conclusions.

\footnotetext{
${ }^{39}$ Lon Fuller (n 11) 231.

${ }^{40}$ Henry M Hart and Albert M Sacks (n 3) 1125.

41 Thomas Bustamante, 'Revisiting the Idea of Protestant Interpretation' in Thomas Bustamante and Thiago L Decat, Philosophy of Law as an Integral Part of Philosophy (Hart Publishing, 2020), 123. See also Frederick Schauer, 'A Critical Guide to Vehicles in the Park' (2008) 83 New York University Law Review 1109, 1130-31; Fabio P Shecaira, 'Sources of Law Are Not Legal Norms' (2015) 28 Ratio Juris 15, 26.
} 
Finally, while sometimes both intentionalism and objective purposivism converge on the same purpose, as seems to be the case in Yates, at other times they diverge. Imagine that all members of a legislature vote to approve a law, but a majority voted to achieve some morally suspect goal, with a minority supporting the same law in order to achieve something that is clearly morally desirable. In this scenario, intentionalism and objective purposivism come apart. While the first stance would identify the rule's purpose with the goal pursued by the majority, that goal is clearly morally inferior to the one intended by the minority. Hence, the divide between both kinds of purpose attribution strategies is consequential, rendering potentially divergent results. The situation is even more complex, however, because there is still a third factor that might go into purpose attribution judgments: current practice.

\section{Current Practice}

Suppose that someone creates a rule with morally laudable ends in mind. Over time, however, the same person starts using the same rule to achieve a completely different - and morally evil - goal. Both objective purposivists and intentionalists would identify the purpose of the rule with the initial goal. But there is also a possible view according to which the rule's purpose might be identified with the second, more recent goal.

This third view says that the purpose of a rule is determined by current practice. That is, the purpose of a rule at any given time is determined by what people actually use the rule for at that time. What we will call "current practice purposivism" therefore differs from objective purposivism in that it says that the purpose of a rule is determined by non-moral facts. However, it also differs from intentionalism in that it makes a very different claim about which facts are the relevant ones. According to current practice purposivism, we do not find the purpose of a rule through a historical inquiry that explores facts at the time the rule was first enacted. Rather, we find it through an inquiry that explores facts about how the rule is used right now.

In spite of its intuitiveness, current practice purposivism hasn't been fully fleshed out by legal scholars. ${ }^{42}$ As a result, we have a much coarser understanding of it. For instance, what are the non-moral facts about the present that drive current practice purposivism? One possible answer

\footnotetext{
42 For a recently developed view that is in many ways similar to the idea of current practice purposivism, see Hillel Y Levin, 'Contemporary Meaning and Expectations in Statutory Interpretation' (2012) University of Illinois Law Review 1103.
} 
would be that the relevant facts are facts about straightforward behavioral regularities, while another would be that they are facts about the norms that guide people's conduct (understood, e.g., in terms of Hart's 'internal point of view $\left.{ }^{43}\right)$. While future work should drill down on this specific distinction, we opted to experiment with the version of current practice purposivism that is most likely to influence people's intuitions, thus employing vignettes where the relevant actors change not only in behavior, but also in beliefs and attitudes.

We also don't know who is capable of changing a rule's purpose. In our hypothetical scenario, the same person is both the creator of the rule and the one who changes the practice surrounding it. Is this feature important, or can other people (e.g., the subjects of the rule) bring about a change in purpose? All of these questions are important and should be worked out by future scholarship. Regardless of specific answers to each of them, however, there is one distinctive feature that sets all more specific forms of current practice purposivism from the other alternatives: for current practice purposivists, what determines a rule's purpose are facts about the present.

\section{Summary}

In summary, legal theorists have argued for at least three different versions of purposivism: intentionalism, objective purposivism, and current practice purposivism. We reviewed arguments for two such positions that are mostly normative and deal with reasons that are specific to the legal domain: intentionalists defend their stance pointing towards legislative supremacy and objective purposivists might hold their ground based on the alleged moral superiority of the results engendered by this sort of interpretation. However, all three positions can be defended with reference to the requirement of publicity in arguments that draw parallels between purpose attribution in law and in ordinary life. This raises the question: how do people attribute purposes outside the legal domain?

\section{Purposes in Cognitive Science}

Within the field of cognitive science, there is a sophisticated literature about how people ordinarily think about purposes. Thus far, this literature has not looked directly at people's ways of thinking about the purposes of laws or rules. It has been concerned instead with people's ways of thinking

\footnotetext{
${ }^{43}$ Hart, (n 10), 56-58; See also S Shapiro, 'What is the internal point of view?' (2006) 75 Fordham Law Review 1157.
} 
about the purposes of objects of other types. There have been numerous studies on people's way of thinking about the purpose of physical artifacts, such as candles, shovels or staplers. ${ }^{44}$ There has also been important work on attributions of purposes to naturally occurring objects, such as when people attribute purposes to biological organs or to the world as a whole. ${ }^{45}$ A central goal within this research has been to develop a unified account of the ascription of purposes that applies across all of these different domains.

Although existing research has explored many different aspects of people's way of thinking about purposes, our concern here will be with the criteria people use to determine what the purpose of an object is. Research on this question almost always uses more or less the same methodology. Experimental participants are introduced to an object and given a brief vignette that provides some information about it. Participants are then asked a question about the purpose of the object. By systematically manipulating aspects of the information in the vignette, researchers can explore the factors that influence people's judgments about purpose.

\section{A. Original Intentions vs. Current Practice}

One of the most important questions explored within research using this method has been whether people's intuitions are influenced more by original intention or by current practice. To address this question, researchers tell participants about an object (e.g., a canister with a spout). They inform participants that this object was originally created to be used for one purpose (e.g., for pouring tea). but that it is now being used for some other purpose (e.g., for watering plants). Participants are then asked about the purpose of the object. Research on this issue has been proceeding for decades, and

\footnotetext{
${ }^{44}$ Adee Matan and Susan Carey (n 1); Tim P German and Susan C Johnson (n 1); Deborah R Siegel and Maureen A Callanan (n 1); David Rose, 'Persistence Through Function Preservation' (2015) 192 Synthese 97; Sehrang Joo, Sami Yousif, and Joshua Knobe (n 1).

45 Deborah Kelemen, 'The Scope of Teleological Thinking in Preschool Children' (1999) 70 Cognition 241; Deborah Kelemen, 'Are Children "Intuitive Theists"? Reasoning About Purpose and Design in Nature' (2004) 15 Psychological Science 295; Tania Lombrozo and Susan Carey, 'Functional Explanation and the Function of Explanation' (2004) 99 Cognition 167; Konika Banerjee and Paul Bloom, 'Why did this happen to me? Religious believers' and non-believers' teleological reasoning about life events' (2014) 133 Cognition 277; Konika Banerjee and Paul Bloom, “Everything Happens for a Reason”: Children's beliefs about purpose in life events' (2015) 86 Child Development 503; Emily G Liquin and Tania Lombrozo, 'Structure-function Fit Underlies the Evaluation of Teleological Explanations' (2018) 107 Cognitive Psychology 22; David Rose and Shaun Nichols, 'Teleological Essentialism' (2019) 43 Cognitive Science e12725; David Rose and Shaun Nichols 'Teleological Essentialism: Generalized' (2020) 44 Cognitive Science e12818; Andrew J Roberts, Colin A Wastell and Vince Polito, 'Teleology and the Intentions of Supernatural Agents' (2020) 80 Consciousness and Cognition 102905.
} 
at this point, a great deal is known about how people respond in experiments using this sort of paradigm. ${ }^{46}$

In early studies on the topic, participants would be told that an object was created to be used for one purpose, and they would then be informed that one specific person began using it for another purpose. For example, an inventor created an object called a "tog" so that it could be used to capture bugs. Now someone owns the tog, but she uses it to collect raindrops. So, what is the purpose of the tog? Is it for catching bugs or for collecting raindrops? Studies using this paradigm consistently found that participants said the purpose of the object was the purpose for which it was originally created. ${ }^{47}$ This result might seem to suggest that people's judgments about purpose are shaped more by original intention than by current practice.

But subsequent studies indicate that there might be more to the story. In these studies, participants are not simply told that one individual person began using the object in a different way. Rather, they are told that there is an established practice within a larger community of using the object in a different way. For example, certain metal tubes were originally created to be used as drinking straws. Then people in the community decided together that they would no longer use the tubes as drinking straws and that they would begin using them exclusively as windchimes. So, what is the purpose of the tubes? Are they for drinking, or are they for making sounds? Studies using this latter approach find that experimental participants tend to say that the purpose of the object is the purpose for which it is being used now. ${ }^{48}$ In other words, people's judgments about the purpose of an object do not seem to shift around if one individual person begins using the object in a different way, but they do seem to shift when there is an established practice within a larger community of using the object in a different way.

A key question now will be whether this sort of result arises for intuitions about laws and rules. One plausible view would be that original intentions are important for laws in a way that they are not for physical artifacts (see section 2) and that people's judgments about the purpose of a law are therefore shaped more by original intentions. Another plausible view would be that judgments about the purposes of laws are very similar to judgments about the purposes of physical artifacts and

\footnotetext{
46 Adee Matan and Susan Carey (n 1); Tim P German and Susan C Johnson (n 1); Deborah R Siegel and Maureen A Callanan (n 1); Sehrang Joo, Sami Yousif and Joshua Knobe (n 1).

47 Adee Matan and Susan Carey (n 1); Tim P German and Susan C Johnson (n 1).

48 Deborah R Siegel and Maureen A Callanan (n 1); Sehrang Joo, Sami Yousif and Joshua Knobe (n 1).
} 
show the same effect of current practice. We will be exploring this question in the experiments reported below.

\section{B. Moral Purposes}

Perhaps more importantly, when we turn to thinking about attributions of purposes to laws, we find ourselves confronted with a new question about attributions of purposes. As we have seen, existing work on the purposes of laws emphasizes not only original intention and current practice but also morality. A question therefore arises as to whether moral considerations play a role in attributions of purpose.

We can distinguish two aspects of this question. First, there is a question about the role of morality in ordinary judgments of purpose. Consider a case in which people are trying to determine the purpose of a physical object. For example, suppose that we are looking at a physical wall and trying to determine what its purpose is. There might be some reason to think that it has a morally good purpose (e.g., protecting people from danger) and also some reason to think that it has a morally bad purpose (e.g., excluding people as a sign of contempt). As we have seen, existing research has explored the question as to whether people's judgments about such cases are influenced by original intention or by current practice, but a further question arises as to whether such judgments are influenced by moral considerations. Other things being equal, would people show a general tendency to be more willing to attribute a morally good purpose than to attribute a morally bad purpose?

As far as we know, there has been no empirical research on this issue. Given the sorts of objects that have been explored within the existing cognitive science literature (teapots, windchimes, etc.), the question regarding moral considerations presumably has not been especially salient. Thus, this question remains an open one.

Yet, although there has not been any research about the impact of moral considerations on purpose judgments, there has been research about the impact of moral considerations on other, perhaps related judgments. Some studies indicate that people have a tendency to see objects as having a morally good essence, ${ }^{49}$ and some theories draw a close connection between judgments

\footnotetext{
49 Julian De Freitas et al, 'Normative Judgments and Individual Essence’ (2017) 41 Cognitive Science 382.
} 
about essence and judgments about purpose..$^{50}$ Moreover, at a more general level, recent research has demonstrated an impact of moral considerations in a number of legally important concepts, including the concept of causation, the concept of the reasonable person, ${ }^{51}$ and the concept of law itself. $^{52}$ Overall, then, there is at least some reason to think that moral considerations might play a role in judgments of purpose.

Second, there is a question about how this more general cognitive science research relates to the way that people think about laws in particular. To illustrate, compare (a) a physical wall that keeps people from going onto someone's property and (b) a law that prevents people from going onto someone's property. People seem to have certain criteria for ascribing purposes to physical objects, and we can ask whether morality plays a role in those criteria. The answer to this question should help us understand how people attribute purposes to a physical object like a wall. But now consider what happens when we replace the wall with a law. A question arises as to whether people would still use the same criteria or whether they would begin thinking about this issue in an importantly different way.

One plausible view would be that the role of morality is exactly the same in judgments about laws as it is in judgments about physical objects. Perhaps people have certain cognitive capacities that they use for attributing purposes, and they use precisely the same capacities for thinking both about physical objects and about laws. By contrast, an alternative view would be that morality plays a distinctive role in judgments about laws that it does not play in judgments about physical objects. For example, it might be that people show a tendency to think about laws in particular in terms of morally good purposes. Or it might be that lawyers gradually acquire, over years of legal training, a refined understanding of the criteria used to attribute purposes to laws that differs in important respects from their criteria for attributing purposes to other sorts of objects.

\section{Summary}

\footnotetext{
50 David Rose and Shaun Nichols, 'Teleological Essentialism' (n 41); David Rose and Shaun Nichols, 'Teleological Essentialism: Generalized' (n 41).

51 Kevin P Tobia (n 7).

52 Brian Flanagan and Ivar R Hannikainen, 'The Folk Concept of Law: Law Is Intrinsically Moral' (2020) Australasian Journal of Philosophy DOI: 10.1080/00048402.2020.1833953.
} 
Existing research in cognitive science has taught us a lot about how people attribute purposes. In the present studies, we draw on this existing research and then extend it in new directions that are especially relevant for work on attributions of purposes to laws.

One important contribution of existing research has been the development of a method that can be used to determine which factors influence people's attributions of purpose. Research using that method indicates that attributions of purpose to physical objects are influenced more by current practice than by original intention. The present studies draw on this method to address some further questions.

\section{Experimental Studies}

In this section, we report the results of four studies that explore the impact of three different factors - original intentions, current practice and morality - on judgments about the purposes of rules and physical objects. The aim is to test the predictions made by legal purposivists and to better understand the ways in which purpose attribution in law is similar to, or different from, the attribution of purposes to objects of other types.

\section{A. Study $1 \mathrm{~A}$}

To investigate whether morality plays a role in purpose attribution, we set up an experiment involving all three kinds of purposivism. We described things that changed over time, in a way that something originally created to achieve a morally good [bad] goal was subsequently used to achieve something morally bad [good]. We further manipulated whether the thing was a physical object (e.g., a physical wall) or a rule (e.g., a rule prohibiting trespassing).

\section{(i) Methods}

151 participants in the United States were recruited through MTurk and completed the experiment in exchange for monetary compensation. We excluded 6 participants who failed the comprehension checks, which resulted in a final sample of 145 (mean age $=36.87,50$ women, 2 non-binary) participants.

In a 2 (type: rule, artifact) $\times 2$ (direction of change: good first, bad first) between- $\times 4$ (scenario: mines, pump, lock, gloves) within-subjects design, participants viewed a set of four scenarios in a randomized order. Each participant viewed four vignettes in a random order, and each 
vignette was paired with a unique combination of object type (Artifact/Rule) and direction of change (Improvement/Deterioration). Thus, participants viewed all four scenarios and all four treatments exactly once. For instance, one participant might get the following four vignettes: 1) type: Rule, order: Deterioration, scenario: Mines; 2) type: Artifact, order: Deterioration, scenario: Pump; 3) type: Rule, order: Improvement, scenario: Lock; 4) type: Artifact, order: Improvement, scenario: Gloves.

The vignettes described a rule (or artifact) that was created to serve a morally good (or bad) goal. Whenever the rule or artifact was first envisioned as morally good, the vignette described a deterioration, substituting the benevolent goal with one that was morally worse. In contrast, whenever the first goal was morally bad, the vignette described a change that represented an improvement, such that the original set of morally bad goals was replaced with morally good ones.

For instance, consider the "Mines" scenario in the Deterioration condition, with the object type changes inside brackets:

\section{Mines}

Lord Bacon was an aristocrat who lived in a mansion in the middle of a very large estate. Neighboring the estate lived several poor families. The poor families often walked through the property.

One day, Lord Bacon discovered a land mine while walking through his property. Although the mine didn't explode, several other mines, which were planted during World War II, were later found on the estate. With this in mind, Lord Bacon [created a rule fining trespassers a large amount of money/built a wall around his property], aiming to protect poor people from accidents involving the mines. The [rule/wall] was successful, as no accidents with mines ever occurred.

Over the years, Lord Bacon became prejudiced against poor people. The sight of poor people walking across his fields was repulsive to him. He began using the [rule/wall] as a way to allow only nobles inside his property. He announced this to close friends saying: "I don't care at all about protecting poor people against accidents involving the mines. All I care about is allowing only nobles inside." The [rule/wall] was successful, as only nobles entered the property. 
After reading each vignette, participants were asked to imagine a disagreement about what the purpose of the rule is and to indicate whether they agree or disagree with each perspective on two separate scales ranging from 1: "Strongly Disagree" to 7: "Strongly Agree".

Two friends familiar with the story had a heated debate about the purpose of the [rule/wall]. One of them said: "The purpose of the [rule/wall] is clearly to allow only nobles inside the property". The other rejoined: "Even though Lord Bacon is using the [rule/wall] for this now, that's not at all what it is really for. The purpose of the [rule/wall] is to protect poor people from accidents involving the mines."

After reading about the situation and the debate, please rate the following two statements (7-point Likert scale):

1) the purpose of the [rule/wall] is to protect poor people from accidents involving the mines.

2) the purpose of the [rule/wall] is to allow only nobles inside the property.

The two statements describing the good and bad purposes were presented in a random order for each scenario. Participants gave independent ratings of each purpose. Participants also answered a comprehension question about each scenario and indicated their age, gender, and legal expertise.

This design allows us to discover what form of purposivism best describes the way people attribute purposes. For instance, if people think that purposes are the same as the original intentions of the designer of a rule or artifact, then they would always prefer the statement describing the first historical goal, no matter whether it was good or bad. In contrast, if people think that purposes should be determined by looking at current practice, the most recent goal would always be preferred, regardless of moral valence. Finally, if the objective purposes view is accurate in describing people's intuitions, participants would prefer the morally good goal over the bad one. ${ }^{53}$ Moreover, the manipulation of whether the thing undergoing functional change was a rule or an artifact allows us to test if people attribute purpose to these two kinds of things in the same way.

\section{(ii) Results}

Results are shown in Figure 1. Data analysis for this study relied on a series of linear mixed effects models regressing purpose judgments on direction of change, moral valence and their two-way interaction (entered as fixed factors), while controlling for random effects of scenario and

\footnotetext{
53 This is the hypothesis pre-registered in https://osf.io/qr483
} 
participant. ${ }^{54}$ The code used to generate all models and model comparisons, as well as all vignettes and data are available at: https://osf.io/grv25/?view_only=21999d1a1165403ba2fdc98f4d0ac5bc

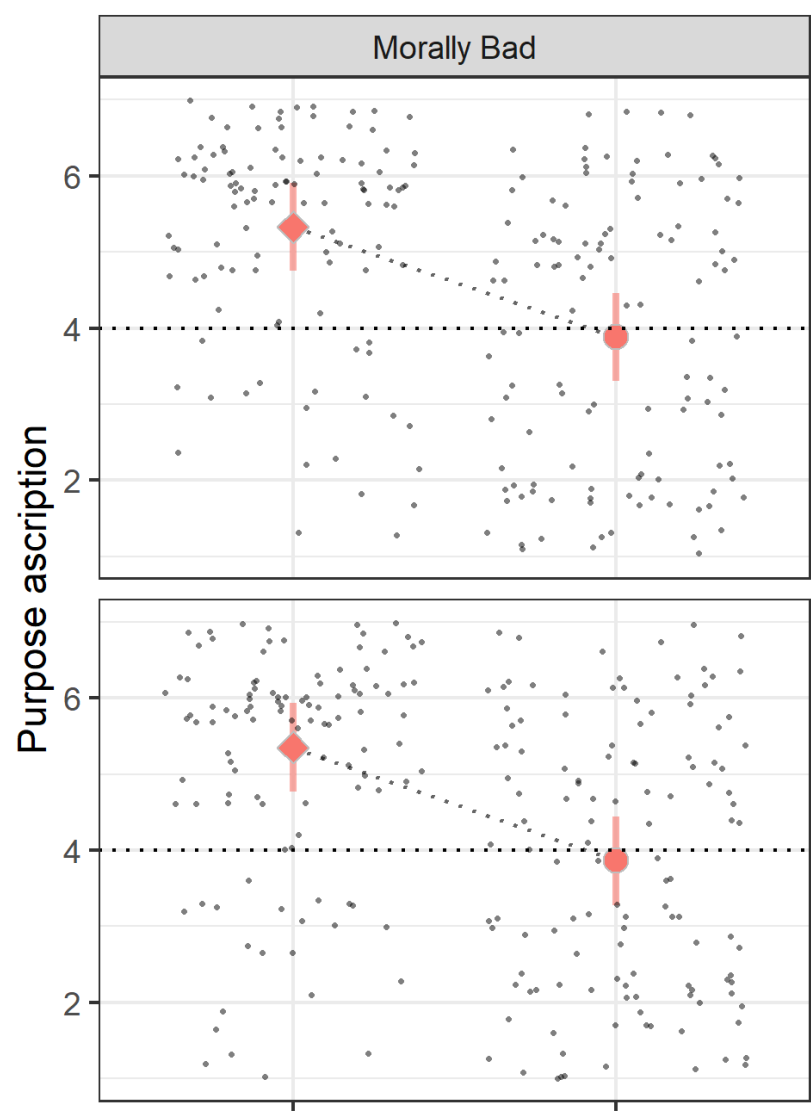

Current practice

Original intentions

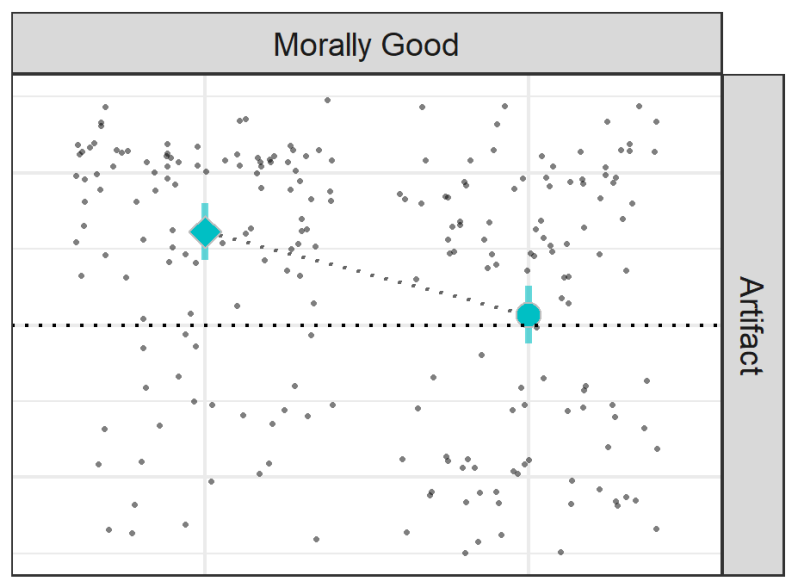

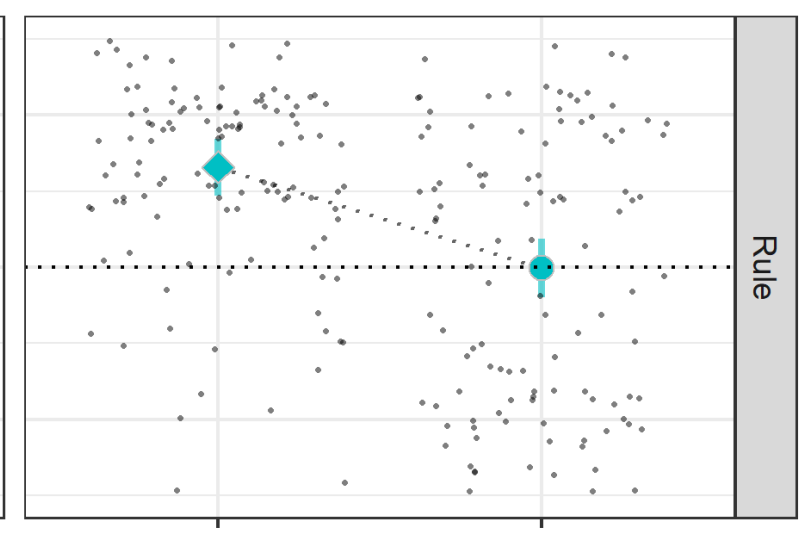

Current practice Original intentions

Figure 1. Laypeople's purpose judgments (y-axis) by criteria (x-axis), moral valence (horizontal facet), and object-type (vertical facet). Error bars in this and all subsequent figures represent the 95\% confidence interval of the estimated marginal means.

First, we asked whether participants tended to think that the purpose of the target (either a rule or an artifact) was (a) the original purpose for which it was created or (b) the purpose it was

\footnotetext{
${ }^{54}$ To simplify the report, we created a variable that encoded the interaction between direction of change and moral valence. Our results are robust to the choice between building the models using the interaction between direction of change and moral valence or a single variable encoding this information as a main effect. For details, see Supplementary Materials.
} 
being used for now. The results showed a clear preference for current purposes, $\chi^{2}(1)=149.01, p<$ .001. When the target went from bad to good, participants were more inclined to say that it had a good purpose, whereas when it went from good to bad, participants were more inclined to say that it had a bad purpose. In other words, independent of anything about the moral status of the different purposes, participants showed a tendency to say that the purpose of the target was whatever it was being used for now.

Second, we asked whether there was an effect of morality. Were participants more inclined to agree that the target had a morally good purpose than they were to agree that it had a morally bad purpose? Strikingly, we found no main effect of morality, $\chi^{2}(1)=0.04, p=.83$. Participants were no less inclined to attribute the morally bad purpose than they were to attribute the morally good purpose.

Finally, we asked whether there was a difference between physical objects and rules. The interaction between object-type and morality was not significant, $\chi^{2}(1)=0.02, p=.89$, indicating that the effect of moral valence did not differ when comparing artifacts to rules. Similarly, the interaction between object-type and purpose-type was statistically non-significant, $\chi^{2}(1)=1.38, p=.24$, suggesting that the preference for current use over original intent was comparable across artifacts and rules. As shown in Figure 1, the patterns look the same whether we are dealing with artifacts or with rules: participants consistently preferred the most recent purpose, regardless of its moral valence and of the direction of change.

\section{(iii) Discussion}

In this first study, we find that participants show almost exactly the same pattern in their judgments about the purposes of ordinary physical objects and their judgments about the purposes of rules. This result provides some initial support for the claim that people have domain-general criteria for attributing purposes, criteria that apply both to physical objects and to rules.

For both physical objects and rules, the results indicated that participants' judgments were not driven primarily by either morality or original intentions. We found no significant effects of morality, and when original intentions were pitted against current practice, participants tend to attribute purposes based on current practice. 
This result is surprising. Even legal scholars who care deeply about publicity have focused much more on original intentions and morality than on current practice as means of determining legal purpose. Similarly, research in cognitive science has tended to emphasize the role of original intentions in purpose attribution. ${ }^{55}$ However, in line with other work, ${ }^{56}$ it seems that both original intentions and moral purposes exert less influence than the current practice in establishing purpose.

What can account for the absence of the predicted effect of morality over attribution of purpose? One possibility is that lawyers might be projecting their own idiosyncratic intuitions onto the general population. Maybe the professional view about purposes is informed by normative arguments, such as the ones reviewed in section 2 , that are likely to be unknown to people outside the legal domain. Taking that into account, we ought to investigate whether lawyers behave as predicted by objective purposivists.

\section{B. Study 1B}

Study $1 \mathrm{~b}$ employed the same stimuli and structure as did Study 1A, but differed in its sampling method. Instead of recruiting participants through MTurk in the US, we recruited lawyers in Brazil through social media and a subset of the mailing lists of reviewers at one prestigious law journal in Brazil (Revista Direito, Estado e Sociedade). Moreover, on the assumption that any effects of legal expertise would arise for rules, but not artifacts, ${ }^{57}$ we focused only on rules in Study $2 \mathrm{~b}$.

\section{(i) Methods}

166 lawyers and law students were recruited for the study. 3 participants failed at least one comprehension check and were excluded. We also excluded 16 participants who reported having no legal training, which resulted in a final sample of 150 (mean age $=37.15,56$ females) participants. ${ }^{58}$

\section{(ii) Results}

\footnotetext{
55 Adee Matan and Susan Carey (n 1); Tim P German and Susan C Johnson (n 1).

56 Deborah R Siegel and Maureen A Callanan (n 1); Sehrang Joo, Sami Yousif and Joshua Knobe (n 1).

57 See Dan Kahan et al, “Ideology" or "Situation Sense”? An Experimental Investigation of Motivated Reasoning and Professional Judgment' (2016) 164 University of Pennsylvania Law Review 349; Kevin P Tobia, 'Law and the Cognitive Science of Ordinary Concepts' in Bartosz Brożek, Jaap Hage and Nicole A Vincent (eds), Law and Mind: A Survey of Law and the Cognitive Sciences (Cambridge University Press, 2021).

58 All participants who reported legal training passed the pre-registered comprehension check.
} 


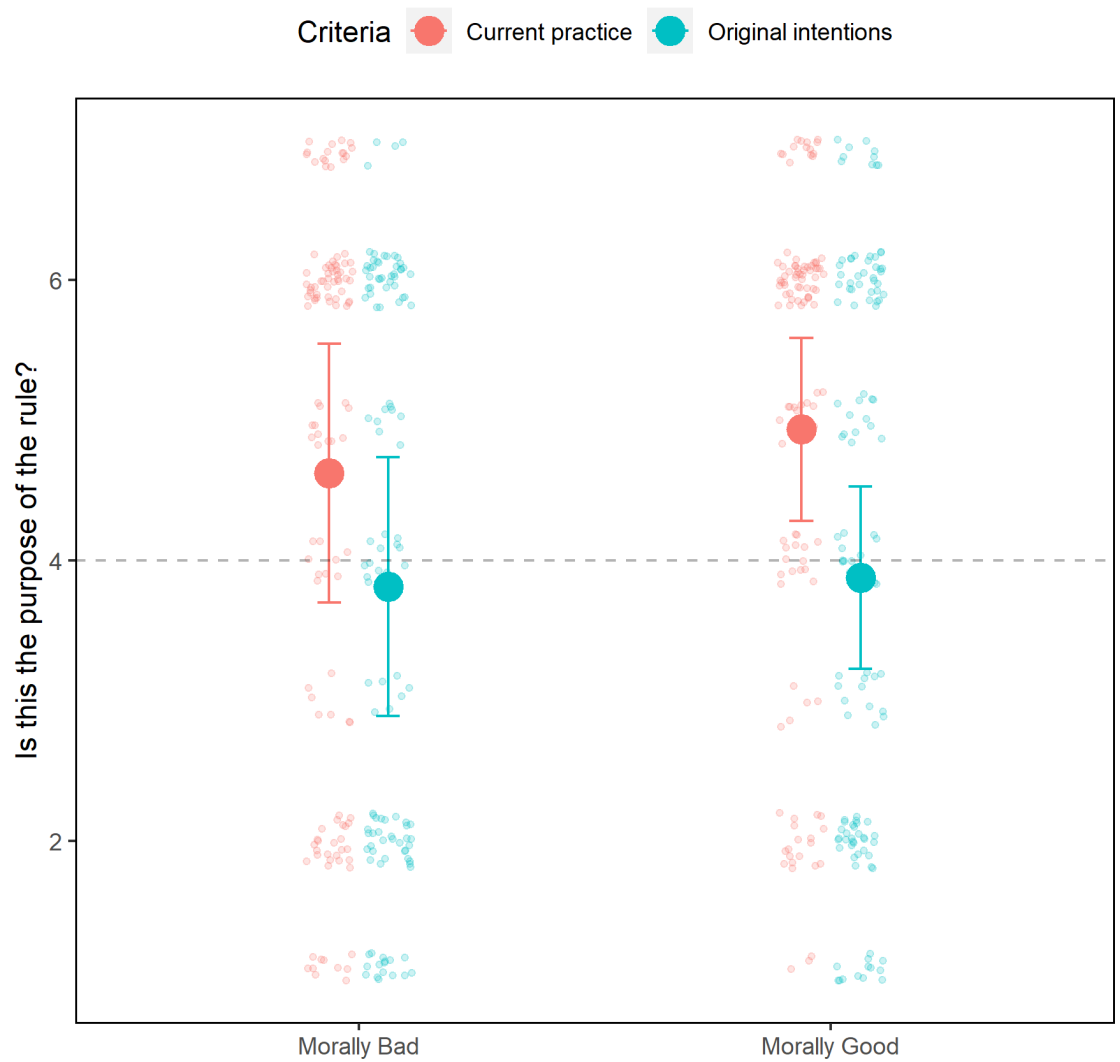

Figure 2. Lawyers' purpose judgments by direction of change and moral valence.

Results are shown in Figure 2. We fitted the same models reported in Study 1A. First, we asked whether lawyers were more influenced by original intentions or by current practice. Lawyers - much like laypeople in Study $1 \mathrm{~A}$ - were more likely to treat the rule's current use as its purpose, $\chi^{2}(1)=$ $29.74, p<.001$.

Once more, there was no significant effect of morality, $\chi^{2}(1)=0.17, p=.68$. Morally bad purposes were just as likely to be seen as the purpose of the rule as morally good ones. The only factor that mattered was whether the purpose was the originally intended one or that which the rule currently serves.

\section{(iii) Discussion}

Across Studies 1A and 1B, we failed to find support for the descriptive claims of moral purposivism in either lawyers or laypeople. Participants from both populations privileged current practice over moral valence and original intentions as the preferred criterion for purpose attribution. This raises the possibility that this clear preference might be overshadowing existing effects caused by the other 
two factors. To account for that, Study 2 investigates situations where there is no clearly convergent current practice surrounding the rule.

Moreover, even though lawyers in Study 1B considered a series of rules - their domain of expertise - the vignettes described situations largely disconnected from settings where purposes are consequential, as is the case in adjudication. Moral purposivists might object to our results by pointing out that moral considerations only become important in contexts where the practical consequences of legal interpretation are salient.

\section{Study $2 A$}

We were struck by the fact that morality had no impact on purpose attributions in Studies $1 \mathrm{~A}$ and $1 \mathrm{~B}$, and we therefore conducted further studies to follow up on that specific finding. For these further studies, we made an important modification that we thought might bring out an effect of morality: we explicitly told participants that the reason people wanted to know about the purpose of the rule was because this purpose attribution would be used in decision-making. Moreover, these further studies did not involve conflicts between original intentions and current practice, thus simplifying their design and focusing on possible effects of morality.

In all scenarios, the intentionalist and objective purposes views rendered divergent purposes. For instance, consider the "housing regulations" scenario:

\section{Housing Regulations}

The city council of Santa Cruz, a city in Brazil, decided by unanimous vote to institute strict housing regulations. A number of slums were forming in the city's hillsides and the bill mandated the removal of all hillside houses and the prohibition of further development on hills. Although every single one of the 50 city counselors supported the bill, different groups of lawmakers voted for this law for very different reasons. 30 lawmakers voted for the bill because they wanted to increase the value of the land near Santa Cruz's downtown, which was depreciating as a result of the slums. The remaining 20 counselors supported the bill because they wanted to protect the poor people living in the slums from landslides, which is something that often takes place in Santa Cruz's hills.

The outcomes of the law show that both objectives were at least partially accomplished. Reports of deaths and injuries resulting from landslides fell significantly, and the value of land near Santa Cruz's downtown has increased back to pre-slum heights. 
All scenarios closed with a paragraph emphasizing that the rule's purpose would be used to aid decision-making. For instance, the "housing scenario" closed with the following paragraph:

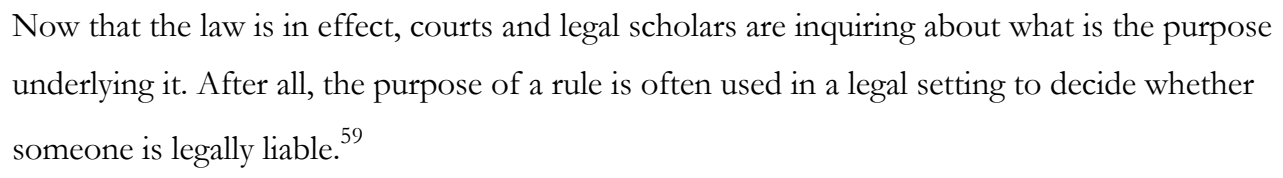

These closing paragraphs also played another important role by making it explicit that there was no clear convergent current practice surrounding the rule's purpose. This is an ecologically valid setting. Many times, the legal discussion about how a new rule ought to be applied - including the debate about its purpose - starts immediately after a new law is passed, and thus much before any practice surrounding it gets the chance to form.

\section{(i) Method}

152 participants in the United States were recruited through MTurk and completed the survey in exchange for monetary compensation. We excluded 7 participants who failed all comprehension checks, and disregarded answers to scenarios where the comprehension check was failed, as preregistered, ${ }^{60}$ which resulted in a final sample of 145 (mean age $=36.69,58$ females) participants.

We came up with a set of four rules that could be used to achieve either morally good or morally bad goals, as illustrated by the "Housing Regulations" scenario. ${ }^{61}$ We then manipulated whether the good purpose was intended by a majority or a minority of lawmakers. So, in the Majority-Moral condition, 30 out of the 50 lawmakers were motivated by the morally good purpose, while the remaining 20 voted for the bill for the wrong reasons. In contrast, in the Minority-Moral condition, a majority enacted the law for morally bad reasons. Finally, in all conditions, we stated that both objectives were at least partially accomplished.

Each participant was randomly assigned to one of the conditions and viewed two out of the four scenarios in a random order. ${ }^{62}$ At the end of each vignette, participants were asked how much

\footnotetext{
59 Studies 2A and 2B included one non-legal scenario, dealing with an internal rule adopted by a university department. Even under that scenario, we primed a future decision-making environment by adding that "Now that the rule was in place, the administrative staff is inquiring about what is the purpose underlying it. After all, the purpose of a rule is often used in an institutional setting to decide what is allowed".

${ }^{60}$ At https: / / aspredicted.org/blind.php?x $=5$ n6b6f.

${ }^{61}$ In some cases, it is possible to argue that we merely contrasted morally good purposes with morally worse, but still not entirely bad, purposes. The overall conclusions, however, would still hold in that case.

62 This means we followed a 2 (majority, minority) x 2 (moral purpose, immoral purpose) between x 4 (scenario) withinsubjects design.
} 
they agreed with a statement describing either the good or the bad purpose on a 7-point Likert scale. Participants also answered one comprehension check for each scenario and questions regarding their age, gender, and legal expertise.

If people take morality into account when thinking about the purposes of rules, morally laudable ends should be preferred, even when they are not supported by a majority of lawmakers. In contrast, if the original intentions of the rule-maker determine the purpose of a rule, then we should expect participants to agree more with the statement describing the goal intended by the majority.

\section{(ii) Results}

Results are shown in Figure 3. We analyzed the data from this study using linear mixed effects models regressing purpose judgments on majority support and moral valence (entered as fixed factors), while controlling for random effects of scenario and participant.

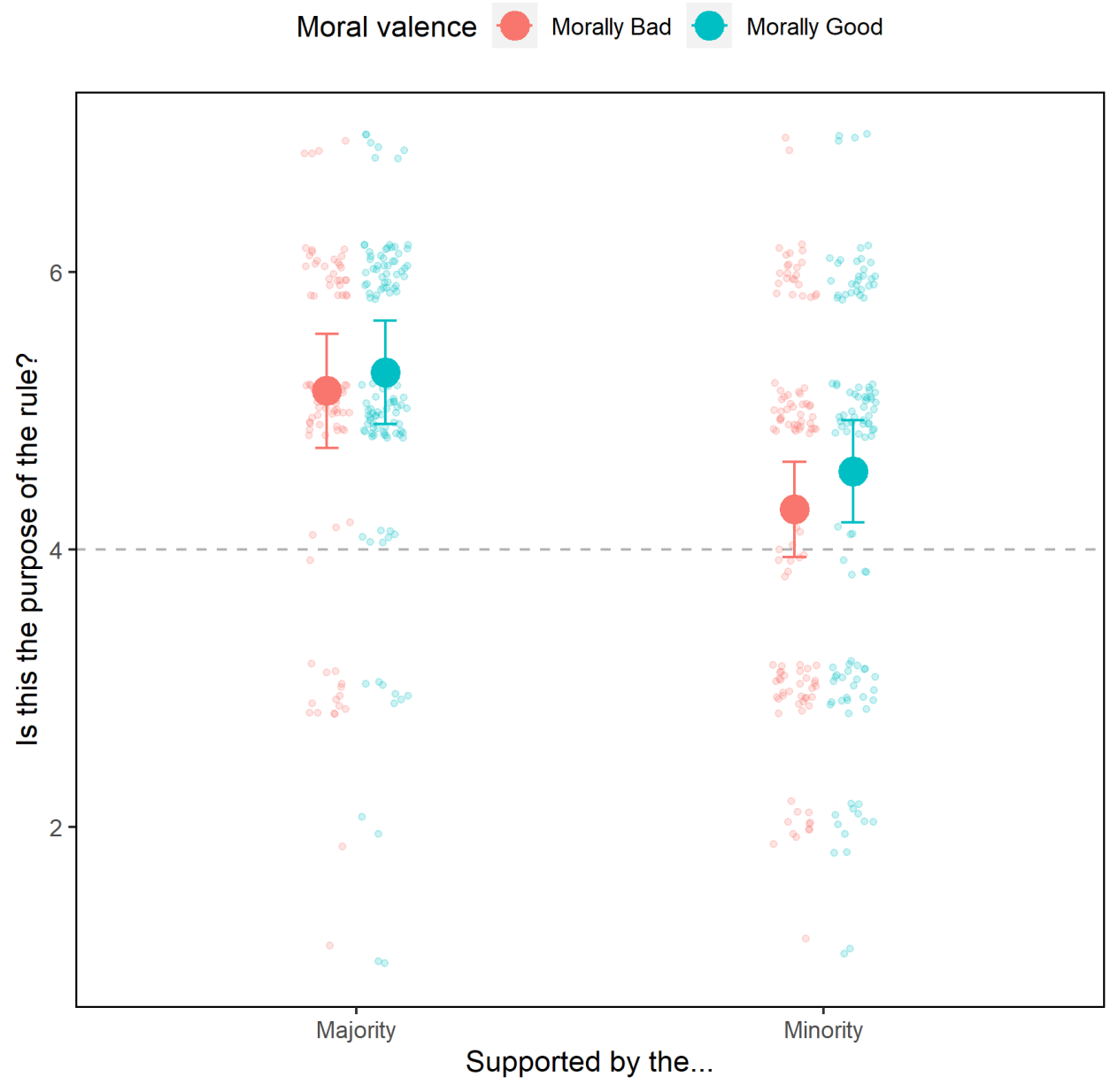


Figure 3. Laypeople's purpose judgments by degree of support and moral valence.

Our analysis revealed a main effect of majority support, $\chi^{2}(1)=40.95, p<.001$. In other words, as depicted in Figure 3, participants were more likely to ascribe the majority supported purpose to the rule (left side of the figure) than the minority supported purpose (right side of the figure). However, we did not observe a main effect of morality, $\chi^{2}(1)=1.08, p=.3$. Participants were just as likely to attribute morally good purposes to a rule as they were with the morally bad candidates. Looking at Figure 3, we can see that there is almost no difference between the green (morally good) and red (morally bad) dots on each condition (Majority-Moral/Majority-Immoral). Finally, there was also no significant interaction between majority support and moral valence, $\chi^{2}(1)=$ $0.33, p=.56$.

\section{(iii) Discussion}

Once again, participants were guided by non-moral factors when attributing purposes to rules. In this case, the overwhelming majority of respondents reported that the purpose of the rule was the one pursued by the majority of lawmakers. This goes to show that even though current practice might exert a larger influence than original intentions under some settings, original intentions are nonetheless an important determinant of purpose. ${ }^{63}$

Interestingly, most participants agreed with the statements describing the purpose, regardless of its moral valence and whether or not it was supported by the majority. In other words, as depicted in Figure 3, mean judgments were higher than 4 - the midpoint of our scale, labeled as "Neither agree, nor disagree" - in all conditions. This suggests that most people think that rules can serve multiple purposes and that the intentions of a minority also matter in shaping them: it isn't the case that the purpose intended by a non-decisive minority of lawmakers is not the purpose of the rule at all; people simply seem to be less willingly to ascribe it to the rule when compared to the purpose intended by the majority.

${ }^{63}$ Alternatively, participants might be taking the original intentions of a majority of lawmakers to be evidence for the practice that will soon form surrounding the rule. On that interpretation, the results would be compatible with the existence of very few intentionalists: the apparent effects of original intentions could be explained by the strength of people's commitment to current practice purposivism. Although interesting, this suggestion seems to assume too much. After all, the vignettes clearly implied the absence of an established practice surrounding the rule. Nonetheless, future research should put this alternative explanation to the test. 
Once again, concerns about expertise effects and the normative reasons specific to the legal domain mandate that a population of lawyers should also be sampled. That was the goal of Study 2B.

\section{Study 2B}

We employed the same stimuli and structure of Study 2A, but instead of recruiting participants through MTurk in the US, we recruited voluntary lawyers in Brazil through a new and nonoverlapping subset of the mailing list of reviewers at one prestigious law journal in Brazil (Revista Direito, Estado e Sociedade), as well as a subset of the mailing list of former students at EPGE, a graduate school for State lawyers in Rio de Janeiro.

\section{(i) Method}

114 participants completed the survey. We excluded 13 participants who reported no legal training and disregarded answers to scenarios where the comprehension check was failed, as pre-registered, which resulted in a final sample of 101 (mean age $=38.82,38$ females) participants. Procedure and hypotheses were the same as Study 1.

\section{(ii) Results}




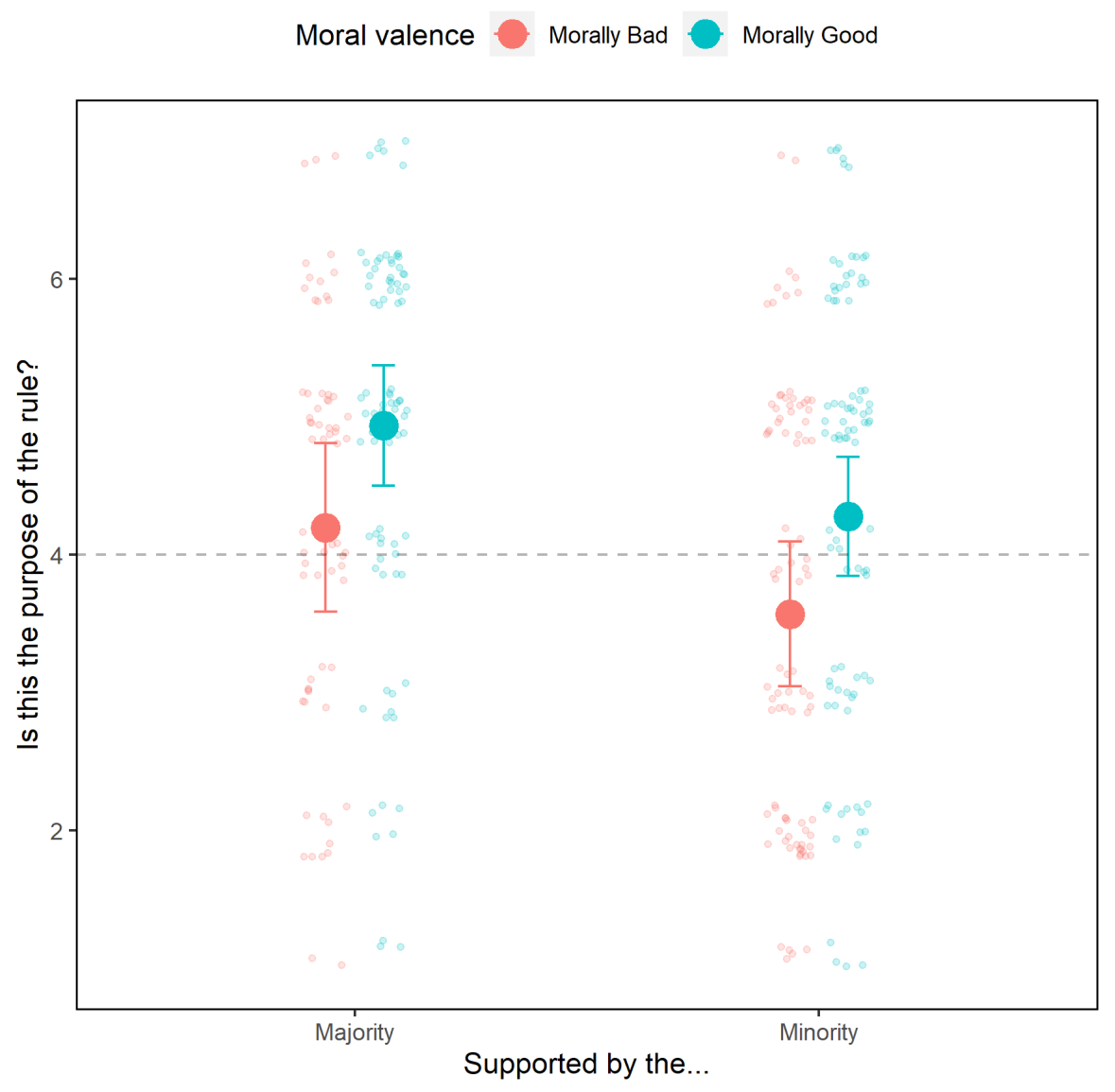

Figure 4. Lawyers' purpose judgments by degree of support and moral valence.

Results are shown in Figure 4. We used the same models reported in Study 2A to perform data analysis for this study. As with Study 2A, we detected a main effect of majority support, such that the goal animating a majority of lawmakers was more likely to be seen as the purpose, $\chi^{2}(1)=$ $14.84, p<.001$. This is represented in Figure 4 by the contrast between the mean responses when the purpose was supported by the majority (left side) and when it was supported by a minority (right side). This time, we also found a main effect of morality, $\chi^{2}(1)=7.34, p<.01$, such that participants were more inclined to attribute morally good purposes to the rule. In Figure 4 this effect is represented by the contrast between the mean responses in the morally good condition (green dots) and those in the morally bad condition (red dots): green dots are overall higher than their red counterparts. Once again, there was no interaction between majority support and moral valence, $\chi^{2}(1)=0.08, p=.93$. 
We now turn to the comparison between Studies 2A and 2B. In both studies, the purpose supported by the majority was preferred by both kinds of participants. However, we could only detect effects of moral valence over purpose attribution in Study 2B. In other words, lawyers systematically preferred moral over immoral purposes.

\section{(iii) Discussion}

Study 2B shows that morality does make a difference to purpose attribution under at least some circumstances where lawyers are the ones surveyed. This difference crosses over the midpoint of our scale when considering purposes supported by the minority. On these occasions, lawyers say that the morally good goals pursued by the minority are the rule's purpose, but morally bad goals intended by them are not. Even though ordinary laypeople do not seem to use morality as a criterion in purpose attributions either to laws or to other objects, trained lawyers do seem to use morality as a criterion in attributing purposes to laws.

Why does that happen? The answer may lie in legal expertise. As Tobia has shown, lawyers often employ specifically legal concepts that have substantial overlap with non-legal concepts designated by the same word in natural language. ${ }^{64}$ In such cases, expertise effects arise when the word is explicitly contextualized within a legal setting, but not under other circumstances. By priming participants to think about the downstream consequences of purpose attribution in Studies $2 \mathrm{~A}$ and $2 \mathrm{~B}$, we hypothesized that participants might moralize purposes. Only lawyers did so, suggesting that there might be a legal concept of purpose that is not identical with its lay counterpart. Future research should strive to further delineate the reasons that differentiate the legal and non-legal versions of purposive interpretation.

In short, the results of Study 2B show that lawyers' attributions of purpose to laws are influenced both by what the majority of the legislators were trying to achieve and by what would be morally best. Taken just in itself, this might not seem to be an especially surprising result, but in combination with Study 1A, it shows something quite striking. It appears that lawyers do sometimes use morality to make attributions of purpose but that, in doing so, they are departing from people's more ordinary criteria for purpose attribution.

\footnotetext{
${ }^{64}$ Kevin P Tobia, 'Law and the Cognitive Science of Ordinary Concepts' (n 52).
} 


\section{General discussion}

We conducted four studies that explored the criteria people use to attribute purposes to laws. These studies examined the impact of original intentions, morality and current practice. The design of the studies made it possible to compare judgments about the purposes of laws to judgments about the purposes of physical objects, and also to compare judgments made by ordinary people with no legal training to judgments made by trained lawyers.

The results yielded four major findings. The first is that attributions of purposes to laws and rules were strikingly similar to attributions of purposes to physical objects. In Study 1A, we looked at three different factors (original intentions, morality, current practice), and all three had the same impact on judgments about laws that they did on judgments about physical objects. Indeed, there were no significant differences of any kind between laws and physical objects.

This finding seems to point toward a larger conclusion about the attribution of purposes to laws. It suggests that the criteria people use in attributing purposes to laws are not specific to the legal domain. Instead, it seems that people attribute purposes to laws by making use of general criteria that they also use when attributing purposes to other objects. If this conclusion does turn out to be correct, it would mean that we can learn a lot about the way people attribute purposes to laws by engaging in a more general investigation into the cognitive science of purpose attribution.

Indeed, even without conducting any new studies, we could potentially gain insights into the nature of purpose attribution in the law simply by leveraging existing findings on purpose attribution for physical objects. For example, existing studies show that people's intuitions about whether a physical object has a given purpose depend in part on whether it is actually effective at achieving that purpose. ${ }^{65}$ And some studies show that people sometimes have intuitions about the purposes of physical objects that they themselves would reject on further reflection. ${ }^{66}$ Further research could explore the implications of these and other findings for questions about legal purposivism.

Our second finding was that in cases where there was a conflict between original intentions and current practice, people's attributions of purpose tended to be guided by current practice. This does not mean that original intentions have no impact. On the contrary, in Studies $2 \mathrm{~A}$ and 2B,

\footnotetext{
65 Sehrang Joo, Sami Yousif and Joshua Knobe (n 1).

66 Kelemen, Deborah, and Evelyn Rosset. 'The human function compunction: Teleological explanation in adults.' (2009) 111 Cognition 138.
} 
people showed a tendency to attribute whichever purpose was endorsed by the majority of legislators, and this result provides evidence that original intentions do have at least some influence ${ }^{67}$ However, in Studies $1 \mathrm{~A}$ and 1B, participants received cases in which original intentions and current practice were in conflict, and in those cases, participants specifically tended to choose the purpose associated with current practice. This tendency arose not only for physical objects but also for laws and rules.

This finding is in marked contrast to the emphasis within the existing literature on purposes in the law. Within that literature, there has been a great deal of emphasis on original intentions ${ }^{68}$ and relatively little emphasis on current practice. The present studies suggest, however, that people's ordinary attributions of purposes to laws are affected more by current practice than by original intentions.

The third finding is the lack of an effect of morality in judgments from ordinary participants with no legal training (Studies 1A and 2A). Even in cases where two different purposes seemed plausible, we found no tendency for people to preferentially choose the purpose that was morally good over the purpose that was morally bad.

This result has implications at two different levels. First, it can be understood as a straightforward finding in cognitive science. Previous research has shown that certain factors influence purpose attributions and others do not. ${ }^{69}$ Such research had not yet explored the impact of morality, and the present studies therefore contribute to our understanding of the cognitive science of purpose attributions by showing that morality is not among the factors that impact purpose attribution. Second, and perhaps more importantly, it can be understood as a contribution to legal scholarship. Certain prominent views about purposes in law suggest that people should attribute purposes to laws in a way that takes morality into account. ${ }^{70}$ The present studies suggest that such an approach to the attribution of purpose would involve a major departure from people's ordinary way of attributing purposes to laws.

Our fourth and last finding is that the present studies provide at least some indication that morality might play a different role in the judgments made by lawyers than in the judgments made

\footnotetext{
${ }^{67}$ But see the caveats laid out in footnote 63.

68 See Larry Alexander and Saikrishna Prakash (n 28); Jeffrey Goldsworthy (n 32).

${ }^{69}$ See section 3.

${ }^{70}$ See section 2 B.
} 
by ordinary people with no legal training. In the studies involving diachronic cases (Studies $1 \mathrm{~A}$ and 1B), neither ordinary people nor lawyers showed an effect of morality. However, in the studies involving synchronic cases (Studies $2 \mathrm{~A}$ and $2 \mathrm{~B}$ ), ordinary people showed no effect of morality, but lawyers did show an effect of morality.

One important limitation of studies $2 \mathrm{~A}$ and $2 \mathrm{~B}$ in that respect is that our populational manipulation conflates expertise and culture. This is a pressing concern, since recent work in crosscultural experimental jurisprudence has found both cultural variation and convergence in intuitions regarding legal concepts. ${ }^{71}$ Further work should replicate the discrepancy between lawyers and laypeople among subjects recruited in the same country.

If the effect is driven by expertise, it is an intriguing finding, which might be worth exploring in further research. On the most basic level, we face a question as to why lawyers showed an effect of morality in Study 2B but not in Study 1B. One plausible hypothesis would be that the difference arises because the materials used in Study 2B specifically emphasized that these judgments of purpose were to be used in adjudicating legal cases. Thus, it might be that lawyers make use of the ordinary criteria for purpose attribution in almost all contexts but depart from those ordinary criteria in contexts where they are concerned with questions about how to adjudicate legal cases. ${ }^{72}$ If that hypothesis turns out to be correct, one interesting possibility is that similar primes might induce people into views that privilege either original intentions or current practice. For instance, instead of telling people that courts and legal scholars are inquiring about what is the purpose underlying a given rule in order to decide whether someone is legally liable (the strategy followed in Study 2B), we could tell them that a group of historians is questioning the purpose of the rule. Under that view, we should then expect participants to be significantly more likely to support an originalist view of purposes.

At a broader level, this finding connects with far more general issues about the relationship between judgments made by lawyers and judgments made by people without legal training. Recent research in a number of different areas has explored the relationship between legal judgment and

\footnotetext{
71 Ivar R Hannikainen et al, 'Are There Cross-Cultural Legal Principles? Modal Reasoning Uncovers Procedural Constraints on Law' (forthcoming) Cognitive Science; Ivar R Hannikainen et al, 'Rules around the world' (in preparation).

72 Even in those cases, it might be that lawyers would still prefer current practice over the other alternatives in such a strong way as to nullify the effects of moral purposes. According to that alternative reading of the data, it is the conjunction of Study 2's explicitly adjudicatory setting with the absence of a clear current practice alternative that makes lawyers turn to morality.
} 
ordinary judgments. ${ }^{73}$ This research indicates that legal judgments tend overall to be very similar to ordinary judgments but also depart from ordinary judgments in certain specific respects. As we continue exploring these phenomena in various specific areas, we will presumably come gradually to have a better understanding of the relationship between legal judgments and ordinary judgments more generally. For instance, subtle interactions between specific kinds of legal judgments (e.g., about intentional action, or about purposes) and areas of law (e.g., criminal law, or constitutional law $)^{74}$ may play an important role in determining similarities and differences between lay and professional intuitions. At this point, however, it is difficult to know with precision what drives these expertise effects.

\section{A. Implications}

The present findings suggest that people's ordinary criteria for purpose attribution emphasize current practice over original intention and show little or no impact of morality. Thus, the results suggest that any approach that emphasizes original intention over current practice, or that includes a role for morality, represents a departure from people's ordinary criteria for purpose attribution. We can now ask what implications this finding might have for questions about legal interpretation.

\section{(i.) The current practice view}

One possible view would be that there are strong reasons for the law to make use of people's ordinary criteria for purpose attribution (e.g., publicity), and we therefore should change our account of legal interpretation so that it better accords with the criteria implicit in people's ordinary attributions of purpose. If we adopt this first view, we will need to make major changes in our understanding of purposivist legal interpretation. We will have to reject an approach based on original intentions or moral purposes, and we will instead have to adopt an approach that includes a role for current practice. Existing research on purposivist legal interpretation has not explored the use of current practice in nearly as much detail as it has explored the use of original intentions and

\footnotetext{
73 See existing research on the concepts of consent (Roseanna Sommers, 'Commonsense Consent' (2020) 129 Yale Law Journal 2232), causation (James Macleod, ‘Ordinary Causation: A Study in Experimental Statutory Interpretation’ (2019) 94 Indiana Law Journal 957; Joshua Knobe and Scott Shapiro, 'Proximate Cause Explained: An Essay in Experimental Jurisprudence' (2021) 88 The University of Chicago Law Review 165), and intentional action (Kevin P Tobia, 'Legal Concepts and Legal Expertise' < https://papers.ssrn.com/sol3/papers.cfm?abstract id=3536564> accessed 22 July 2021 ; Markus Kneer and Sacha Bourgeois-Gironde, 'Mens rea ascription, expertise and outcome effects: Professional judges surveyed' (2017) 169 Cognition 139).

74 See Walter Sinnott-Armstrong, 'A Patchwork Quilt Theory of Constitutional Interpretation' in Tom Campbell and Jeffrey Goldsworthy (eds), Judicial Power, Democracy and Legal Positivism (Routledge, 2016).
} 
moral purposes. Thus, if we conclude that legal interpretation should make use of the ordinary notion of purpose, we will need to shift our attention toward an array of questions about the use of current practice that have not been a central topic within existing research.

The vignettes used in our experiments were constructed in such a way that every aspect of the current practice converged on a single purpose, but in real life, things can be considerably more complex. Often, different aspects of the current practice will point toward different purposes. A fullblown theory of legal interpretation based on the notion of current practice would therefore have to explain in detail how to resolve these conflicts.

To begin with, a question arises about which specific facts constitute the practice. In our vignettes, an authority's behaviour indicated a purpose which the authority explicitly endorsed. In real life, these two factors can come apart. For example, suppose there is a statute in the criminal law such that (a) if one simply does a statistical analysis of the behavioral regularities, one finds that this statute is being used to prosecute people of a particular ethnic group but (b) if one looks at the ways in which officials are required to justify or give reasons for their actions, one finds that these acts of reason-giving always emphasize the goal of preventing violence. Now, if a judge wants to interpret this law in terms of the purpose given by current practice, should she interpret the law in terms of the goal of prosecuting people of a particular ethnic group or in terms of the goal of preventing violence?

Although very important, answering this specific question would still leave many important details open. For instance: different legal actors (judges, police officers, prosecutors, or those who hold no office) might adopt different practices (either with or without adopting an internal point of view) about a single law. If we imagine that the law in question is a federal statute in a federation such as the U.S., even occupants of the same office in different states might develop incompatible practices. What would be the purpose of the federal law in those two cases?

These are all difficult questions that can conceivably be answered in many different ways. Moreover, they merely scratch the surface of what would be required to provide a fully developed version of current practice purposivism. Our goal in bringing all of this up is not to provide answers, or even to enumerate some of the paths that future scholars might take. Instead, we aim to emphasize that current practice purposivism still needs a lot of work before it is capable of guiding decision-makers to the same extent that intentionalism and objective purposes are. However, given 
our finding that ordinary people attribute purposes to rules using some form of current practice purposivism, this would be work well worth doing.

\section{(ii.) Intentionalism and objective purposes}

A second possible view would be that this finding indicates that the criteria for purpose attribution used in legal interpretation ought to depart in systematic ways from the criteria used in more ordinary non-legal judgments. People have criteria that they use when attributing purposes to ordinary objects (a wall, a pair of gloves), but within the practice of legal interpretation, the concept of purpose plays a quite specific role, and one might well think that this role is not well served by the criteria people appear to be using in their ordinary attributions. Instead, one might think that it is best served by the criteria articulated within existing theories of legal interpretation, such as the criteria developed within existing work on intentionalism or objective purposivism.

This second possible view would allow us to hold onto intentionalism or objective purposivism, but it would force us to reconceptualize these doctrines. As we saw above, the existing literature has sometimes framed these doctrines in terms of claims about the ordinary concept of purpose. If we accept the second view, we might still describe our strategy using the word "purpose", but we should be clear that we are not using that term in its ordinary meaning. Rather, we would be introducing a technical concept that is specific to the law. This technical concept might be similar in some ways to the ordinary concept of purpose, but it would also differ from that concept in important respects.

The question we face here is perhaps best understood as just one example of a far broader issue that has arisen in numerous different areas within the emerging field of "experimental jurisprudence". ${ }^{75}$ In numerous different cases, the law makes use of concepts that people also employ outside of the legal domain. Experimental jurisprudence researchers then explore how the ordinary concept works, how the legal concept works, and how they two might be similar or different. Existing research has employed this approach for the concepts of consent ${ }^{76}$ causation, ${ }^{77}$

\footnotetext{
75 See Roseanna Sommers, 'Experimental Jurisprudence' (2021) 373 Science 394 and Kevin P Tobia, 'Experimental Jurisprudence' (Forthcoming) 89 University of Chicago Law Review, for recent reviews.

${ }^{76}$ Roseanna Sommers (n 73).

77 James Macleod (n 73); Joshua Knobe and Scott Shapiro (n 73).
} 
the reasonable person, ${ }^{78}$ and intention. ${ }^{79}$ Often, the result is that the legal concept is similar in many ways to the ordinary concept but also differs in certain important respects. A question then arises in each case as to whether it would be better to bring the legal concept more closely into line with the ordinary concept or whether there are good reasons for the legal concept to differ from the ordinary concept.

In the particular case at hand, our question is whether the law should depart from people's ordinary criteria for purpose attribution by attaching greater weight either to original intentions or morality. In thinking about this question, it might be helpful to focus especially on the ways in which the legal context differs from more ordinary contexts. Do any of those differences give us a reason to depart from the criteria that people use for purpose attribution in more ordinary life?

When it comes to original intentions, it does seem that there is at least some plausible basis for this claim. After all, in many other domains, it might be seen as appropriate for people to make judgments in a way that accords with their own values, but one might plausibly think that the context of legal interpretation is deeply different. In legal interpretation, one might think, the courts should not be making judgments based on their own values but should instead defer to the values of the legislature, e.g., for reasons related to democratic ideals. ${ }^{80}$ As we have seen, this is sometimes referred to as the doctrine of legislative supremacy.

Clearly, there would be no analog to the doctrine of legislative supremacy in most ordinary contexts in which people make purpose attributions. Suppose that you purchase some gloves from a manufacturer and that you are later faced with a question about the purpose of these gloves. There would be no plausible justification in such a case for a doctrine of "manufacturer supremacy," i.e., for a doctrine according to which one must always defer to the purposes envisioned by the original manufacturer. Instead, it would make perfect sense for you to substitute your own judgment for the judgment of the corporation that manufactured the gloves. Defenders of intentionalism could plausibly argue that legal decision-making is radically different in this respect and that we therefore have reason to depart from the ordinary criteria for purpose attribution in favor of distinctive legal criteria that reflect the legislature's special role.

\footnotetext{
78 Kevin P Tobia, 'How People Judge What Is Reasonable' (n 7).

79 Kevin P Tobia, 'Legal Concepts and Legal Expertise' (n 73); Markus Kneer and Sacha Bourgeois-Gironde (n 73).

${ }^{80}$ For an argument to that effect, see Jeremy Waldron, 'The Core of the Case Against Judicial Review' (2006) 115 Yale Law Journal 1346, 1349-50.
} 
Objective purposivists might also emphasize ways in which law is dissimilar to other realms to argue for their preferred method of purpose attribution. First, there are the direct practical implications. Purpose attribution in law is distinctive in that it might carry very serious implications. Nothing moral turns on whether the purpose of a car is to carry people or cargo, but a lot can turn on whether the purpose of a rule is to increase the value of property or to protect people from landslides. Hence, objective purposivists can argue for a departure from ordinary purposivism on the basis of moral correctness: in law, it is especially important to ensure morally good results; so, no matter what the ordinary intuitions of people are, we ought to attribute the purposes best suited to achieve those ends. As we saw, current practice purposivism would sometimes detract from this goal, since the most recent current practice surrounding a rule might be morally bad. Then, secondly, there might be more conceptual arguments. Very often objective purposivists such as Fuller and Dworkin defend an intrinsic link between law and morality. If law, unlike other domains,${ }^{81}$ is conceptually tied to morality, it is reasonable to argue that purpose attribution in law should be informed by moral evaluation, no matter what ordinary people think about it. Hence, even if it is not a mistake to use current practice or original intentions to devise purposes in other domains, it could be a mistake to do so in law.

These are plausible arguments that turn on the specialness and relative importance of competing normative goals. But they have not been clearly deployed in the existing literature. As we have seen, existing work often claims that people's ordinary practice of purpose attribution is accurately captured either by intentionalism or by objective purposivism. We have argued that this claim is false. Both of these views involve a departure from people‘s ordinary purpose attributions. Thus, there might be a good reason to adopt one or another of these views, but to provide an adequate argument for them, one cannot rely on claims about people's ordinary practices. One needs to explain why the criteria for purpose attribution in the law should differ from the criteria for purpose attribution that people employ in ordinary life.

\footnotetext{
${ }^{81}$ But see Lon Fuller, 'Human Purpose and Natural Law' (1958) Natural Law Forum 68, arguing that all purposeful action, even outside law, implies a blurring of the "ought" / "is" distinction.
} 